\title{
PROFESSOR DOS ANOS INICIAIS: ARTICULAÇÕES ENTRE POLIVALÊNCIA, INTERDISCIPLINARIDADE E CURSO DE PEDAGOGIA
}

\author{
Thays Ribeiro Guedes, Vanda Moreira Machado Lima \\ Universidade Estadual Paulista - UNESP, Curso de Licenciatura em Pedagogia, Presidente Prudente, SP. E-mail: \\ thaysguedes170@gmail.com.
}

\begin{abstract}
RESUMO
Este artigo é resultado da articulação de três pesquisas e visa refletir sobre o professor dos anos iniciais enfatizando o conceito de polivalência, interdisciplinaridade e curso de Pedagogia. As pesquisas utilizaram como base para formação conceitual e conclusiva a pesquisa documental na legislação educacional dos cursos de Pedagogia, a pesquisa exploratório-descritiva para analisar 144 matrizes curriculares de cursos de Pedagogia no Estado de São Paulo e o relato das autoras do artigo. Notamos nas legislações uma definição no que tange aos conhecimentos profissionais docentes de forma geral, contudo tanto a legislação estadual como a nacional silenciam-se em relação à questão do professor polivalente dos anos iniciais lecionarem diferentes disciplinas, e principalmente como assegurar a interdisciplinaridade nos cursos de Pedagogia.
\end{abstract}

Palavras Chave: Curso de Pedagogia. Polivalência. Interdisciplinaridade. Formação Inicial. Professor dos Anos Iniciais.

\section{TEACHER OF INITIAL YEARS: ARTICULATIONS BETWEEN POLIVALENCE, INTERDISICPLINARITY AND PEDAGOGY COURSE}

\begin{abstract}
This article is the result of the articulation of three researches and aims to reflect on the teacher of the initial years emphasizing the concept of polyvalence, interdisciplinarity and course of Pedagogy. The researches used as basis for conceptual and conclusive formation the documentary research on educational legislation of Pedagogy courses, the exploratory-descriptive research to analyze 144 curricular matrices of courses of Pedagogy in the State of São Paulo and authors' report of the article. We note in the legislations a definition regarding professional teaching knowledge in general, but both state and national legislation are silent on the issue of the polyvalent teacher of the early years teaching different disciplines, and especially how to ensure interdisciplinarity in the courses of Pedagogy. Keywords: Pedagogy Course. Multifunctionality. Interdisciplinarity. Initial formation. Teacher of the Initial Years.

Keywords: Pedagogy. Versatility. Interdisciplinarity. Initial Formation. Professor of early years..
\end{abstract}




\section{INTRODUÇÃO}

Para que o ensino se desenvolva com qualidade no complexo contexto da escola pública faz se necessário, dentre vários fatores, uma formação qualificada e sólida aos profissionais da educação, com destaque nesta pesquisa ao sujeito professor dos anos iniciais do ensino fundamental que leciona nas redes municipais diferentes disciplinas, como Língua Portuguesa, Matemática, História, Geografia, Ciências, Artes e Educação Física.

Diante dessas considerações apresentamos uma reflexão sobre três questões que afetam diretamente o professor dos anos iniciais do ensino fundamental: a polivalência, a interdisciplinaridade e o curso de Pedagogia.

\section{METODOLOGIA}

Neste artigo utilizamos o resultado de três pesquisas ${ }^{1}$ desenvolvidas pelas autoras que envolveram a pesquisa documental na legislação educacional dos cursos de Pedagogia, a pesquisa exploratório-descritiva para analisar as matrizes curriculares de cursos de Pedagogia no Estado de São Paulo, e um relato. Contudo os dados empíricos apresentados resultam principalmente da pesquisa de Pimenta e Fusari (2014) que se insere, na abordagem quantitativa e trata-se de uma pesquisa exploratório-descritiva na qual se busca, preponderantemente, a descrição e análise dos dados de forma articulada e aprofundada. Trabalhamos com 144 matrizes curriculares de cursos de Pedagogia no Estado de São Paulo cadastrados no site do Inep/MEC (2012). Elaboramos um instrumento de coleta de dados constituído de duas partes, uma com os dados gerais da instituição e do curso e a outra com várias categorias de análise das matrizes curriculares. A pesquisa passou pelo Comitê de Ética em Pesquisa (CEP) por não envolver seres humanos.

\section{RESULTADOS}

Apresentamos uma reflexão sobre polivalência, interdisciplinaridade e curso de Pedagogia. POLIVALÊNCIA E PROFESSOR DOS ANOS INICIAIS

O termo "professor polivalente" identifica o profissional professor que atua em mais de uma das áreas do conhecimento que compõem o currículo nacional dos anos iniciais do Ensino Fundamental. Ao longo da história, o professor polivalente dos anos iniciais recebeu diferentes identificações, como: "mestre-escola", "mestre régio", "professor das primeiras letras", "professor de instrução primária", "professor do ensino primário", "professor unidocente", "professor multidisciplinar", "professor polidisciplinar", "professor das quatro séries iniciais do 10 grau", "professor das quatro séries iniciais do Ensino Fundamental", "professor polivalente" e "professor do ciclo I". (LIMA, 2007; LIMA, 2012).

Na conjuntura atual do mundo do trabalho, observa-se, de um lado, a defesa entusiasmada da polivalência, requisitada pelo discurso neoliberal no período pós-crise do capitalismo, que foi entendida como atributo do trabalhador contemporâneo, adaptado a contextos diversos e possuidor de competências múltiplas que lhe permitem atuar em diferentes postos de trabalho e em diferentes áreas, agregando, assim, a eficiência e o aumento da produtividade, pautados pela flexibilização funcional. Por outro lado, desenvolve-se um movimento que se caracteriza pela crítica ao trabalhador polivalente e sua formação com base na ideia do trabalhador politécnico. Esse movimento inspira-se em correntes marxistas e tem gerado novos debates e novas propostas no campo educacional, orientando o ensino para um posicionamento crítico às atividades produtivas baseadas nos fundamentos da ciência. (CRUZ; BATISTA NETO, 2012).

\footnotetext{
${ }^{1}$ As três pesquisas são: 1) pesquisa interinstitucional na qual fui pesquisadora, financiada pelo CNPq envolvendo 17 pesquisadores que objetivou analisar a forma de organização dos cursos de Pedagogia do Estado de São Paulo visando identificar qual o tratamento dado aos conhecimentos relacionados à formação do professor para atuar nos campos da educação infantil e nos anos iniciais do ensino fundamental (PIMENTA; FUSARI, 2014); 2) pesquisa individual na qual investiguei a formação do professor polivalente para os anos iniciais do Ensino Fundamental, priorizando um estudo de caso no curso de Pedagogia da FCT/UNESP (LIMA, 2016) e a 3) pesquisa em andamento que coordeno, financiada pela PROGRAD/UNESP que visa refletir sobre a interdisciplinaridade na atuação do professor dos anos iniciais (2017).
} 
$\mathrm{Na}$ análise da legislação educacional, o termo polivalente se faz presente no Parecer CNE/CEB no 16/99 (BRASIL, 1999) que estabelece diretrizes aos cursos de ensino profissionalizante, no qual a polivalência profissional é compreendida como atributo de um profissional, como competências para superar os limites de uma ocupação e poder transitar para outros campos ou ocupações da mesma área profissional, ou seja, "permite ao profissional transcender a fragmentação das tarefas e compreender o processo global de produção, possibilitando-lhe, inclusive, influir em sua transformação (BRASIL, 1999, p. 37)".

Compreendemos que a polivalência evidencia a presença do discurso neoliberal; entretanto, a expressão "professor polivalente" utilizada com frequência no chão das escolas públicas municipais do interior do estado de São Paulo precisa ser discutida, visto que é uma realidade, mas se ausenta nas legislações e nas discussões dos cursos de Pedagogia.

Subsidiados por Cruz e Batista Neto (2012), analisamos a polivalência nas salas de aulas dos anos iniciais no processo de escolarização formal, enfatizando alguns elementos, como:

Relação professor e aluno: nesta perspectiva, a polivalência garantiria a formação de uma pedagogia global que objetiva atender tanto às necessidades e interesses do aluno como incentivar o professor a perceber os conhecimentos de maneira integral. O fator tempo seria um facilitador, uma vez que o professor teria um período maior de contato com os alunos, identificando assim suas particularidades e retomando conteúdos ainda não apreendidos.

Especialização e generalização: referimo-nos a uma tensão, entre a busca por uma especialização em relação às áreas de conhecimento do currículo básico da escolarização inicial e a defesa da formação e atuação geral de um único professor no ensino das diferentes áreas.

Polivalência oficial e real: verificamos que se, por um lado os documentos oficiais se silenciam sobre a polivalência integral, visto que o currículo oficial dos anos iniciais se constitui por sete disciplinas, por outro lado, no interior das escolas públicas, os professores vivenciam a polivalência real, sem clareza de como debater essa condição. Inclusive apontam a dificuldade em elaborar sete planos de ensino anualmente para cada disciplina.

Interdisciplinaridade: o termo se faz presente nos documentos oficiais como uma necessidade de formação, mas sem especificar sua compreensão, ou mesmo como assegurá-la e desenvolvê-la nos cursos de formação. Além disso, percebemos a valorização de algumas disciplinas, em detrimento de outras, principalmente quando consideradas as avaliações externas.

CURSO DE PEDAGOGIA E A INTERDISCIPLINARIDADE

Desde a sua criação, em 1939 o curso de Pedagogia passou por várias legislações educacionais que provocaram alterações em sua estrutura e objetivos, além de suscitarem reflexões, discordâncias e pesquisas. Ainda que não se tenha definido claramente sua identidade, mas percebe-se que, historicamente, que a docência é o foco dos cursos de Pedagogia no Brasil.

$O$ curso de Pedagogia, em âmbito nacional, fundamenta-se na recente Resolução CNE/CP no 2/2015 (BRASIL, 2015) e na Resolução CNE/CP no 1/2006 (BRASIL, 2006). Nas universidades públicas estaduais há a Deliberação do Conselho Estadual de Educação de São Paulo (CEE) n. 111/2012 atualizada pelas Deliberações CEE 126/2014 e 154/2017. O curso de Pedagogia tornou-se, ao longo do processo histórico, lócus de referência na formação de professores dos anos iniciais do Ensino Fundamental e da Educação Infantil.

Estudos recentes têm evidenciado as fragilidades do curso de Pedagogia. Tais fragilidades decorrem de vários aspectos, como: aligeiramento de conteúdos; pouco tempo para diversas formações (professor e gestor); desarticulação teoria e prática; inadequação da proposta de estágio supervisionado; predomínio da dimensão teórica em detrimento das práticas; ensino idealizado de aluno/escola e professor/ensino, desvinculado da realidade prática de nossas escolas; pouca experiência dos professores com o Ensino Fundamental; distanciamento das instituições de formação com as escolas, futuro espaço de atuação dos professores (PIMENTA, 1999; GATTI, NUNES, 2009; LEITE, LIMA, 2010; PIMENTA, FUSARI, 2014, e outras). 
Em relação aos cursos de Pedagogia no Estado de São Paulo, pesquisamos 144 matrizes curriculares, dos quais $86,80 \%$ (125) são ofertados em instituições privadas e apenas 13,20\% (19) em públicas. Verificamos que 99 cursos estão instalados em Faculdades, 19 em Centros Universitários e 26 em Universidades. Quanto ao tempo de integralização dos cursos, 67 são oferecidos em quatro anos e 75 em menos de quatro anos. Destes últimos, 47 (32,63\%) são ofertados em três anos e dois cursos em mais de quatro anos. Os "[...] cursos de menor duração (seis semestres) são predominantemente oferecidos pelas instituições privadas, ou seja, 43 (91,49\%) dos 47 privados" (PIMENTA; FUSARI, 2014, p. 13).

$\mathrm{Na}$ pesquisa de Pimenta e Fusari (2014), conforme tabela 1 constatou-se que os "Conhecimentos integradores", definidos com o objetivo de identificar nos cursos perspectivas de organização curricular integradora e/ou interdisciplinar, foram encontrados em um índice baixo, o que mostra a prevalência nos cursos investigados da perspectiva disciplinar fragmentada.

Tabela 1. Distribuição da Carga Horária das Matrizes dos cursos de Pedagogia

\begin{tabular}{l|c}
\hline \multicolumn{1}{c}{ Categorias } & carga horária \\
\hline 1. Conhecimentos relativos aos fundamentos teóricos da educação & $16,41 \%$ \\
\hline 2. Conhecimentos relativos aos sistemas educacionais & $5,64 \%$ \\
\hline 3. Conhecimentos relativos à formação profissional docente & $38,12 \%$ \\
\hline $\begin{array}{l}\text { 3.1 Conhecimentos relativos às áreas disciplinares sem especificação do nível de } \\
\text { ensino }\end{array}$ & $23,77 \%$ \\
\hline 3.2 Conhecimentos relativos à Educação Infantil & 4,63 \\
\hline 3.2.1 Áreas disciplinares /Linguagens na Educação Infantil & $2,41 \%$ \\
\hline 3.2.2 Outros conhecimentos da Educação Infantil & $2,22 \%$ \\
\hline 3.3 Conhecimentos relativos aos anos iniciais do Ensino Fundamental & $1,65 \%$ \\
\hline 3.3.1 Áreas disciplinares no Ensino Fundamental & $1,20 \%$ \\
\hline 3.3.2 Outros conhecimentos do Ensino fundamental & $0,45 \%$ \\
\hline 3.4 Conhecimentos relativos à Educação Infantil e Ensino Fundamental & $1,43 \%$ \\
\hline 3.5 Conhecimentos relativos à Didática & $6,64 \%$ \\
\hline 4. Conhecimentos relativos à Gestão Educacional & 6,73 \\
\hline 5. Conhecimentos relativos ao estágio supervisionado e às práticas de ensino & $4,57 \%$ \\
\hline $\begin{array}{l}\text { 6. Conhecimentos sobre ações de pesquisa e Trabalho de Conclusão de } \\
\text { Curso/Monografia }\end{array}$ & $6,78 \%$ \\
\hline 7. Conhecimentos relativos às modalidades de ensino, às diferenças, à diversidade \\
e às minorias linguísticas e culturais
\end{tabular}

Fonte: PIMENTA; FUSARI, 2014, p.14-15.

Observamos a quase inexistência de uma organização curricular que integre as áreas de conhecimento, por meio de projetos integradores e/ou atividades em que os estudantes possam dialogar, na prática futura profissional, com as aprendizagens construídas nas diferentes disciplinas. A não previsão de uma organização curricular com tais características nos cursos de Pedagogia pode deslocar para a responsabilidade dos estudantes uma ação inerente à formação do professor polivalente e do desenvolvimento de atividades interdisciplinares, no que se refere principalmente à integração entre áreas de conhecimento oriundas de diferentes saberes.

A fragilidade dos cursos de Pedagogia se intensifica quando damos voz aos seus alunos concluintes. Apresentamos a seguir o relato de uma aluna do 4을 ano do curso de Pedagogia, autora desse artigo que expõe a ausência do estudo sobre interdisciplinaridade. 
[...] há uma fragilidade na integração dos currículos, com conteúdos fragmentados, dificultando a aprendizagem e impossibilitando os alunos adquirir os saberes em conjunto. Apenas no terceiro ano do curso, houve uma breve fala sobre o assunto, sem o aprofundamento em textos para a real importância da relação entre as disciplinas [...] Entendo que a interdisciplinaridade seja uma comunicação entre o conteúdo de várias disciplinas, acontecendo quando os conteúdos estudados sejam compreendidos pelos alunos de forma significativa. Acredito que seja um desafio para as Universidades desenvolverem essa abordagem na prática, entretanto a interdisciplinaridade pode ser uma inovação na prática pedagógica do professor.

Para Fazenda (2011, p. 76) a interdisciplinaridade representa "uma mudança de atitude na forma de conceber, compreender e entender o conhecimento, uma troca em que todos saem ganhando, uma vez que há uma mudança de atitude por parte dos envolvidos".

A interdisciplinaridade abrange a área da educação e tem como finalidade, romper com a fragmentação dos saberes, favorecendo maior interação entre as ciências e o conhecimento, responder à necessidade de superação da visão fragmentada dos conteúdos de disciplinas escolares discute questões curriculares, ensino e aprendizagem. A interdisciplinaridade

[...] caracteriza-se pela intensidade das trocas entre os especialistas e pelo grau de integração real das disciplinas [...] consiste em lançar uma ponte para ligar as fronteiras que haviam sido estabelecidas anteriormente entre as disciplinas com o objetivo preciso de assegurar a cada uma seu caráter propriamente positivo, segundo modos particularidades e com resultados específicos (JAPIASSU, 1976, apud THIESEN, 2008, p. 545).

A interdisciplinaridade é um movimento importante de articulação entre o ensino e o aprender, "tem a potencialidade de auxiliar os educadores e as escolas na ressignificação do trabalho pedagógico em termos de currículo, de métodos, de conteúdos, de avaliação e nas formas de organização dos ambientes para a aprendizagem" (THIESEN, 2008, p. 553).

Diante disso, um currículo integrado com a teoria e prática, o rompimento da fragmentação de conteúdos e o diálogo entre educador e educando, além de contribuir para o processo de transformação do ensino e aprendizagem, dá ênfase ao sentido do conceito de interdisciplinaridade.

\section{DISCUSSÃO}

Notamos, nas legislações analisadas sobre o curso de Pedagogia, uma definição no que tange aos conhecimentos profissionais docentes de forma geral, mas não se discute a especificidade da polivalência. Constatamos que tanto a legislação estadual como a nacional silenciam-se em relação à questão do professor polivalente dos anos iniciais lecionarem diferentes disciplinas. Nas matrizes curriculares dos cursos de Pedagogia no Estado de São Paulo constata-se a presença ínfima de propostas de interdisciplinaridade.

O que se conclui é algo tão corriqueiro quanto dramaticamente verdadeiro: a formação profissional de professores para os anos iniciais requer, imediatamente, a reformulação dos currículos [...] Vive-se no Brasil, no âmbito da formação de docentes, um estranho paradoxo: professores dos anos iniciais do ensino fundamental, que precisam dominar conhecimentos e metodologias de conteúdos muito diferentes, como Português, Matemática, História, Geografia, Ciências e, à vezes, Artes e Educação Física, não recebem esses conteúdos específicos em sua formação, 
enquanto que os professores dos anos finais, preparados em licenciaturas específicas, passam quatro anos estudando uma só disciplina, aquela em que serão titulados (LIBÂNEO, 2010, p. 580-581).

Como formar no curso de Pedagogia um professor para atuar com qualidade no contexto atual das escolas públicas? Como assegurar no curso de Pedagogia uma formação qualificada e sólida aos professores dos anos iniciais? Como assegurar no curso de Pedagogia domínio dos conhecimentos das sete disciplinas que se constituem o currículo oficial dos anos iniciais do ensino fundamental? Como assegurar vivências no curso de Pedagogia que foquem a interdisciplinaridade e a reflexão sobre a polivalência?

\section{CONCLUSÃO}

Ser professor dos anos iniciais significa ser, estar e sentir-se polivalente. A polivalência constitui a essência do trabalho desse profissional. Ser professor polivalente nos anos iniciais significa apropriar-se de conhecimentos diversos inerentes ao ato de formar e educar crianças de 6 a 10 anos de idade, ensinar, interagir e dialogar com elas no processo ensino e aprendizagem. Significa adquirir conhecimentos gerais que envolvem a docência nesta faixa etária e de conhecimentos específicos que compõem a base comum do currículo nacional. O professor polivalente não é apenas o somatório das áreas do conhecimento; somos muito mais. 0 polivalente representa, portanto, um profissional com múltiplos saberes, capaz de transitar com propriedade e conhecimento em diferentes áreas (LIMA, 2007).

\section{REFERÊNCIAS}

BRASIL. MINISTÉRIO DA EDUCAÇÃO. CONSELHO NACIONAL DE EDUCAÇÃO. Resolução CNE no 2/2015. Institui as Diretrizes Curriculares Nacionais para a formação inicial em nível superior (cursos de licenciatura, cursos de formação pedagógica para graduandos e cursos de segunda licenciatura) e para a formação continuada. Disponível em:

<http://www.abmes.org.br/legislacoes/visualizar/id/1750>. Acesso em: 19 jul. 2015

BRASIL. MINISTÉRIO DA EDUCAÇÃO. CONSELHO ESTADUAL DA EDUCAÇÃO. Resolução CNE/CP no 1/2006. Institui Diretrizes Curriculares Nacionais para o Curso de Graduação em Pedagogia, licenciatura. Brasília: MEC/CNE, 2006. Disponível em: <http://portal.mec.gov.br>. Acesso em: 10 mar. 2010.

BRASIL. Ministério da Educação. Conselho Nacional de Educação. Câmara de Educação Básica. Parecer no 16, de 5 de outubro de 1999. Institui Diretrizes Curriculares Nacionais para a Educação Profissional de Nível Técnico. Diário Oficial da União, Brasília, DF, 26 nov. 1999.

CRUZ, S. P. S.; BATISTA NETO, J. A polivalência no contexto da docência nos anos iniciais da escolarização básica: refletindo sobre experiências de pesquisas. Revista Brasileira de Educação, Rio de Janeiro, v. 17, n. 50, p. 385-499, mai-ago. 2012.

GATTI, B. A; NUNES, M. M. R. (Org.) Formação de professores para o ensino fundamental: estudo de currículos das licenciaturas em Pedagogia, Língua Portuguesa, Matemática e Ciências Biológicas. São Paulo: FCC, DPE, 2009.

FAZENDA, I. C. A. Integração e interdisciplinaridade no ensino brasileiro: efetividade ou ideologia. São Paulo: Loyola, 2011. 
LIBÂNEO, J. C. O ensino de Didática, das metodologias específicas e dos conteúdos específicos do ensino fundamental nos currículos dos cursos de pedagogia. Revista Brasileira de Estudos Pedagógicos, Brasília, v. 91, n. 229, p. 562-583, set./dez. 2010.

LIMA, V. M. M. Formação do professor polivalente dos anos iniciais no curso de Pedagogia: um estudo de caso na FCT/UNESP. Relatório Técnico de Pesquisa. 2016. Mimeografado.

LIMA, V. M. M. A complexidade da docência nos anos iniciais na escola pública. Nuances: estudos sobre educação - Revista eletrônica do Programa de Pós-Graduação da Faculdade de Ciências e Tecnologia - UNESP, Presidente Prudente, ano XVIII, v. 22, n. 23, p.151-170, maio/ago. 2012.

LIMA, V. M. M. Formação do professor polivalente e os saberes docentes: um estudo a partir de escolas públicas. 280f. 2007. Tese (Doutorado em Educação) - Faculdade de Educação, Universidade de São Paulo, São Paulo.

LEITE, Y. U. F.; LIMA, V. M. M. Cursos de Pedagogia no Brasil: o que dizem os dados do Inep/MEC? Ensino em Re-vista: Dossiê Formação de Professores (Publicação Semestral do Programa de PósGraduação em Educação da Universidade Federal de Uberlândia, MG), Uberlândia, v. 17, n. 1, p. 69-93, jan./jun. 2010.

PIMENTA, S. G.; FUSARI, J. C (et all). A formação de professores para a Educação Infantil e Anos Iniciais do Ensino Fundamental: análise dos currículos dos cursos de Pedagogia de instituições públicas e privadas do Estado de São Paulo. Relatório Técnico de Pesquisa. São Paulo, 2014. Mimeografado.

PIMENTA, S. G. (Org.). Saberes Pedagógicos e atividade docente. São Paulo: Cortez, 1999.

SÃO PAULO. Conselho Estadual de Educação de São Paulo. Deliberação CEE 111/2012 atualizada pela Deliberação 154/2017. Disponível em:

<http://www.ccg.unicamp.br/files/cpfp/legislacao/Deliberao-CEE-111-2012---atualizada-pelaDeliberao-CEE-154-2017-.pdf. >. Acesso em: 01 ago. 2017.

THIESEN, J. S. A interdisciplinaridade com um movimento articulador no processo ensinoaprendizagem. Revista Brasileira de Educação, v.13,n.39, p. 545-598set/dez.2008. 